\title{
Thoracic surgical education in a changing paradigm
}

\author{
Vaughn A. Starnes, MD
}

Members, guests, colleagues, friends, and family, welcome to the 100th annual meeting of the American Association for Thoracic Surgery (AATS). First, I would like to say that I am humbled to be standing before you as the President of this prestigious Society. As your 100th President, I do feel a burden of legacy to those who have preceded me and who through their service made this one of the great and admired professional organizations in the world. So, in many ways, the task forward is clear: to make the AATS even greater. To this end, I believe the cornerstones are the scholarship of our membership and the education of our residents and students of thoracic surgery. The components of the educational process must include not only the technical aspects of surgery but also the aspects of professionalism that are continually threatened by the administrative burden, government oversight, and financial demands of today's practice. We must not forget that it is a privilege and sacred trust to care for patients at a time when they are the most vulnerable.

Cardiothoracic (CT) surgery has been an amazing gift to me. The journey to become a CT surgeon required commitment, tenacity, and rigor. I had many role models and mentors who aided me along the way. My father and mother were great role models. They encouraged me to dream, gave me a work ethic by example, and made sacrifices to ensure my education. It saddens me they cannot be here today and share this moment.

Dr John Sawyers, Chief of Surgery of Vanderbilt University during my residency, demonstrated the confidence of a mentor in his mentee. I was the chief resident on Dr Sawyers' service and was called to the emergency department to see a patient. To my surprise, underneath the white sheet lay Dr Sawyers with the symptom of abdominal pain. He assured me that it was kidney stones and that with intravenous fluids and some pain medications, he would be okay. I

\footnotetext{
From the Division of Cardiac Surgery, Department of Surgery, Keck School of Medicine of USC, University of Southern California, Los Angeles, Calif.

Disclosures: The authors reported no conflicts of interest.

The Journal policy requires editors and reviewers to disclose conflicts of interest and to decline handling or reviewing manuscripts for which they may have a conflict of interest. The editors and reviewers of this article have no conflicts of interest.

Read at the 100th Annual Meeting of The American Association for Thoracic Surgery: A Virtual Learning Experience, May 22-23, 2020.

Received for publication May 13, 2020; revisions received May 13, 2020; accepted for publication May 13, 2020; available ahead of print May 17, 2020.

Address for reprints: Vaughn A. Starnes, MD, Department of Surgery, Keck School of

Medicine of USC, University of Southern California, 1520 San Pablo St, HC2 Suite 4300, Los Angeles, CA 90033 (E-mail: Vaughn.Starnes@med.usc.edu).

J Thorac Cardiovasc Surg 2021;161:713-22 $0022-5223 / \$ 36.00$

Copyright (c) 2020 Published by Elsevier Inc. on behalf of The American Association for Thoracic Surgery

https://doi.org/10.1016/j.jtcvs.2020.05.023
}

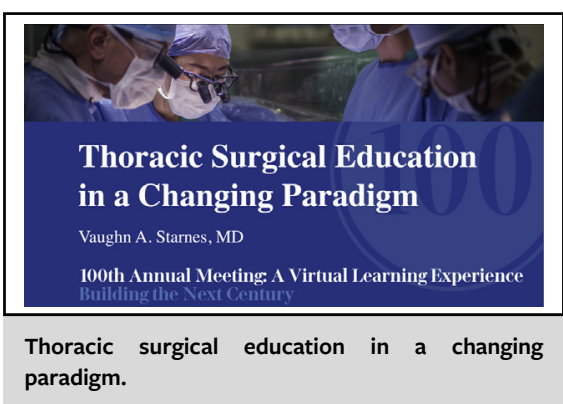

$$
\begin{aligned}
& \text { CENTRAL MESSAGE } \\
& \text { Why does the AATS exist as an } \\
& \text { organization? My answer as your } \\
& \text { president is: to promote schol- } \\
& \text { arship, education, and research } \\
& \text { for the benefit of our patients. I } \\
& \text { believe our membership will be } \\
& \text { critical to modifying training } \\
& \text { programs to address CT surgical } \\
& \text { education in a changing } \\
& \text { paradigm. }
\end{aligned}
$$

performed an examination and found a very tender right lower quadrant. I explained to my chief that I thought he had appendicitis, which he promptly dismissed. I ordered an intravenous pyelogram, which showed no kidney stones. I returned to his bedside with the news, and I thought he should be taken to the operating room. He agreed. I asked whom the surgeon should be, and much to my surprise he pointed his finger at me. To explain further, his brothersin-law were very famous general and vascular surgeons in Nashville. Obviously, I had some concern, but he would not change his mind. He said, "I trained you, and I know I will have a great outcome." He obtained emergency privileges for me, and off we went to the operating room. Much to my relief, a very inflamed appendix was found and removed without incident other than my gastric reflux. Although it was just an appendectomy, it demonstrated to me the ultimate bar in surgical education: the pupil operating on the mentor.

Among all my mentors, and there have been many, Dr Norman Shumway, our 67th president, has been the most influential (Figure 1). In 1981, I recall a presentation by Dr Shumway about the first heart-lung transplantation that had just weeks before been performed at Stanford 


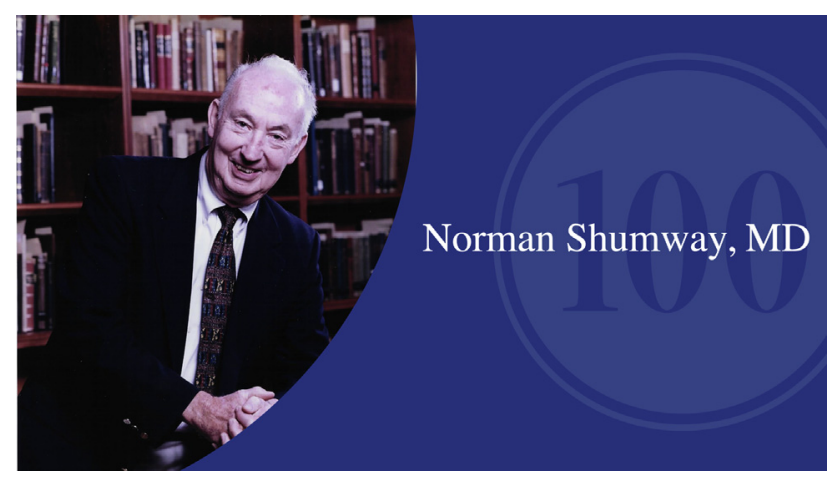

FIGURE 1. Dr Norman Shumway, AATS 67th president.

University by Dr Bruce Reitz. The description of this "first" was inspiring, but it was equally inspiring to watch a proud mentor describe the accomplishment of his student, Dr Reitz. I was a fourth-year general surgery resident and knew I wanted to be a thoracic surgeon and a pupil of this great mentor. I was fortunate and began my training at Stanford in 1984. My 3 years of training at Stanford exceeded my expectations. I was a student of Dr Shumway and his talented faculty: Drs Stinson, Oyer, D. Craig Miller, our 88th president, and Scott Mitchell. In his Presidential Address, "Some Thoughts From the Other Side of the Table, or the Last Presidential Address," Dr Shumway's teaching skills as the world's best first assistant were clearly outlined. He always insisted that the hardest part of surgery was getting to perform surgery. His operating room was a wonderful teaching environment, and his blend of humor and attention to detail to ensure the best possible outcome for the patient are remembered by all of his pupils. His ability to coach a resident through a surgery with complete calm and control left an indelible imprint on me. I try to pass on these "Shumway techniques of teaching" to my residents at the University of Southern California (USC).

I thank my faculty and staff in the Department of Surgery, the Divisions of Cardiac and Thoracic Surgery at USC, and the faculty at Children's Hospital, Los Angeles, whose support has made this day possible. I thank my administrative assistant, Claudia Guzman, for all of her assistance, and the administrative team of the AATS, who have been so helpful this year. Last, but most important, my family.

Julie, you have been the "wind beneath my wings" this year with your understanding and support during the long hours at the office and my absence from home by travel. Thank you.

My children, Kristen and her husband Jeff, Ashley and her husband Jon, Meg and her husband Julian, Rich and his wife Corey, and Chris and her wife Kary, Andrew, and my 11 grandchildren, thank all of you for your support.

I am going to spend this address discussing the following: First, I am going to review the history of the AATS, because I think a brief history of our heritage is important to set the stage for understanding the essential cornerstones of the AATS: scholarship, innovation, and education of our residents and students. We must remember that the prism through which we look at the past is often a template for the present and the future.

Next, I am going to review the history of surgical education programs. Although our field of thoracic surgery has expanded exponentially, our training paradigms have remained rather stagnant. To understand more fully why this might be, I think review of the residency in America should be presented. Then I am going to talk about the history of our surgical programs as it relates to the challenges that we face with our current training paradigm. Last, I will discuss the factors that I think should be considered as we move forward to improve our current training model. As I go through this review, I want all of you to ask yourselves this question: What changes have you made to your training program over the past 5 years?

Thoracic education has always been one of the cornerstones of the AATS. From its founding in 1917 by Willy Meyer, the mission has been to bring those physicians interested in diseases of the chest together for discussion and exchange of information for the betterment of their patients (Figure 2). Dr Meyer presented a paper at the 1913 clinical conference of the American Medical Association entitled "Extrathoracic and Intrathoracic Esophagoplasty in Connection With Resection of the Thoracic Portion of the Esophagus for Carcinoma," and much to his dismay, there was no discussion. He believed that this new evolving discipline needed its own society formulated by physicians and surgeons interested in diseases of the thorax.

Over the next 4 years, Dr Meyer spurred colleagues interested in thoracic diseases to form a New York Society of Thoracic Surgery. They met on February 20, 1917, at his home on Madison Avenue. There were 2 tasks: to establish the New York Society, but more important, to establish a national society. The first meeting included 20 members. As dictated by Dr Meyer, there were surgeons, a radiologist, a pulmonologist, an endoscopist, a physiologist, and an internist caring for patients with tuberculosis.

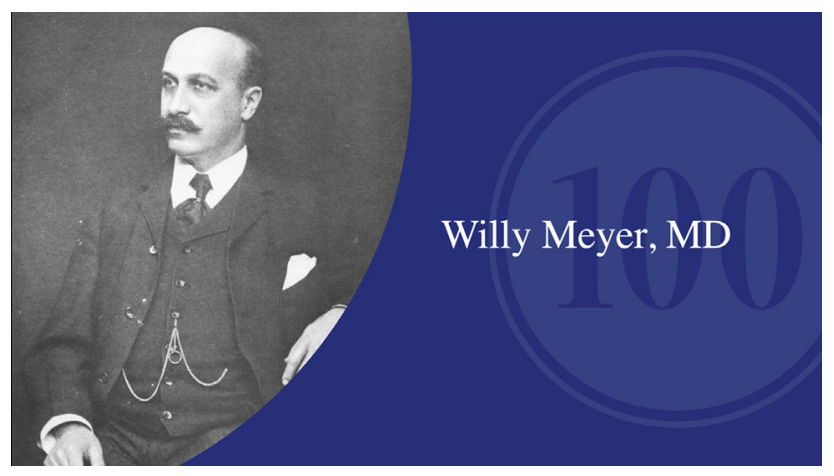

FIGURE 2. Dr Willy Meyer, AATS founder. 
A committee was immediately formed to scour North America for men who had published in the field of thoracic surgery and related fields, and to invite them to New York City for the formation of the AATS. This meeting occurred on June 7, 1917, at the Hotel Waldorf-Astoria. Another 42 names were proposed for membership. Dr Meyer's dream of a national society was taking shape. The following specialties were included: Anatomy, Physiology, Pathology, Internal Medicine inclusive of pulmonary tuberculosis, Gastroenterology, Endoscopy, Anesthesia, and Surgery.

The first president was Dr Samuel J. Meltzer, a physiologist and an internist, who had written extensively on intratracheal positive pressure intubation and its aid in opening the thorax for surgical procedures. These pioneers had formulated a society where they could come together at an annual meeting to discuss and exchange ideas for the care of patients with thoracic diseases. At this time, the topics were mainly tuberculosis and empyemas. Their dream was that the diseases of the chest would gain equal importance to those of the abdomen.

The modern surgical residency as we know it can be traced back to William Halsted and the Johns Hopkins training program. With the opening of the Johns Hopkins Hospital in 1889, William Halsted, William Osler, and Howard Kelly had established residencies in surgery, medicine, and gynecology. ${ }^{1}$ These residencies were the first in America. Before that, advanced training in medicine had to be obtained in Europe, mostly in Germany and France. The Hopkins residencies were established for the scientific study of the physiologic consequences of disease. Thus, training had finally entered the university. As stated by Osler, "The residency is only for a few superior men wishing to do scientific work." Apologies to the women here today; he said it in 1889. Clinical work as they saw it was a byproduct of this intense study. The residency was set up as a 12-month internship, and if the candidate proved worthy, a second year of residency, and ultimately a chief residency serving the attending staff for an undetermined period. The surgical residency was an apprenticeship model, where the chief resident served until the faculty thought he was ready for independent practice. The clinical units were residentrun, with faculty supervision. The residents would diagnose, plan a course of treatment, and operate. To ensure that only the best became chief residents, a pyramid structure was in place such that only a few of the interns finished as chiefs.

It was during these early years, as medical information was expanding at an exponential rate, that surgical subspecialties were recognized. Halsted understood early on that an in-depth knowledge of a particular area demanded subspecialization. He appointed Hugh Young to urology; Samuel Crowe to ear, nose, and throat; William Baer to orthopedics; and Harvey Cushing and Walter Dandy to neurosurgery.
Thus began the differentiation of surgery into subspecialties for concentrated study. Surgical training in the 1920s and 1930s was vocational training in most institutions. The Johns Hopkins model, with its focus on research and clinical investigations, ensured that residency training had entered the university model of graduate-level training and physician competency. The goal as stated by the Hopkins faculty was not to produce "scientists" or "practitioners" but rather "scientific practitioners." The educational objective was for all residents to develop a spirit of inquiry, rigorous intellectual honesty, and intellectual dissatisfaction for present knowledge. ${ }^{1}$ I would refer any of you interested in this topic to Kenneth Ludmerer's book Let Me Heal: The Opportunity to Preserve Excellence in American Medicine. ${ }^{1}$

This model of training became very popular and brought great recognition to Johns Hopkins. Other centers adopted this model, such as Peter Bent Brigham, Massachusetts General Hospital, New York Hospital (as the teaching hospital for Cornell), Washington University, St Louis, Vanderbilt, and Stanford. The centers were often established by trainees of Johns Hopkins. The model had been set up so that the intern and first-year residents did the bulk of the clinical work. The chief resident and the faculty did the investigative laboratory work, taught medical students, and administrated.

As America was increasingly becoming more urbanized during the 1920s and 1930s, these hospitals had an everincreasing demand for clinical work. More and more patients were being admitted, and a better understanding of disease and treatment resulted in shorter hospital stays, and thus more clinical demand. This had ripple effects: Residents had less time for clinical investigative work, and residencies were expanding to meet the clinical demand. The focus on scientific discovery was being sacrificed by the increasing demand for clinical work.

By 1940, graduate medical education was a major commitment of every medical school faculty. Hospitals also recognized the importance of the residency programs in that they often brought an elite status to their institution. From 1900 to the beginning of World War I, a resident staff was a luxury in most hospitals, but by World War II, residents had become a necessity. Every hospital now needed a resident staff, and the expansion was accelerating. With the expansion came inconsistency in program quality. Much like the Flexner report of 1910 for medical schools, a setting of standards for resident programs was needed, none more than in surgery. During the 1920s and 1930s, there were several different ways of obtaining a certificate to operate, with wildly varying standards. Many vocational schools required as little as 3 months operating on cadavers and animals.

Obviously, standardization for public safety had to be done. With the support of the American College of 
Surgeons, the American Board of Surgery was established in 1937 to standardize the training of surgeons in America. The American Board of Surgery established criteria of training length, diversity of cases, and number. They then established the written and oral examinations to be given to candidates who had finished these approved programs. After 1942, this was the only pathway to becoming a general surgeon in America.

Residency programs had matured during the 1930s and 1940s, and none more than surgery. With sterile technique, better surgical techniques and instrumentation, and anesthesia, surgery was offering dramatic outcomes for patients with intra-abdominal processes such as appendicitis, colitis, cholecystitis, and even early-stage cancer. With improved outcomes and better training, the public trust was at an all-time high.

The general surgeons of 1930s and early 1940s did not think their skills were confined to the abdomen, but equally applicable to the thorax. This debate between those who believed that thoracic surgery needed its own board and training program was highlighted at the 1936 annual meeting of the AATS. Dr John Alexander delivered a presentation on the training of the surgeon who expects to practice thoracic surgery. ${ }^{2} \mathrm{He}$ described the increasing complexity of cases now being treated in the thorax and noted that many were being performed by surgeons with little training, resulting in poor outcomes. He believed 2 years of intensive training in a very active thoracic unit was required, with a possible third desired for competency. ${ }^{2}$ At the same meeting, Dr Evarts Graham delivered a presentation outlining thoracic training from the general surgeon's perspective. Dr Graham had been instrumental in establishing the American Board of Surgery and held the first certificate ever given. Dr Graham believed that a separate board was not desirable, and if one were to be established it should require general surgery boards first. ${ }^{2}$ Thus, these 2 papers set the groundwork for the establishment of training requirements for thoracic surgery. In 1936, thoracic surgery involved surgery of the lungs, esophagus, and mediastinum and no vascular or cardiac. Although limited in scope compared with today, recommended training involved completion of general surgery and then 2 to 3 years of thoracic surgery (sounds familiar). However desirable, most hospitals could not support a separate thoracic program at this time because of case volume and the fact that cases that were available were being treated by general surgeons.

Thoracic surgery matured during World War II because of the chest injuries that were now being seen as a result of better evacuations from and transfusions in the field. Drs Thomas Buford, Paul Samson, and Lyman Brewer were surgical leaders who made many contributions to the field during this time, such as the explanation of "wet lung," anatomic exposures, and vascular control in the chest. These 3 surgeons would later become AATS presidents. In 1948, the Board of Thoracic Surgery was formed with the support of the AATS, American Surgical Association, American College of Surgeons, and Surgical Section of the American Medical Association. Resident training required 2 years of thoracic surgery training in programs approved by the Board of Thoracic Surgery and completion of an approved general surgery program. The case mix and numbers of cases were not mentioned initially. As thoracic training expanded to include an ever-increasing volume of cardiovascular cases, the requirements became more rigid. A candidate could meet his requirements for dual certification in general surgery and thoracic surgery by completing a number of thoracic cases in his or her fifth year of general surgery training, but this pathway would go away.

In 1969, the Board of Thoracic Surgery adopted a provision requiring 12 months of senior responsibility in thoracic and cardiovascular surgery. In 1971, the independent board of the American Board of Thoracic Surgery was formed. Further clarification of training experience occurred in 1973, when the Residency Review Committee for Thoracic Surgery defined the minimal numbers and diversity of cases that a trainee should perform in a graduated fashion. The minimal number was set at 100 , with 15 to 20 cases involving the lungs and pleura and 30 to 40 cases involving the great vessels and heart, with an emphasis on using cardiopulmonary bypass. Five to 10 cases of the esophagus and diaphragm were recommended. The Residency Review Committee, with the approval of the American Board of Thoracic Surgery, had now clearly outlined the training expectations.

As thoracic training was being defined, residency training in general was facing new challenges. With the enactment of Medicare and Medicaid in 1965 and the rise of private insurers, medical care was now available to more Americans in a more private setting.

Wards with 12 to 14 beds were disappearing rapidly. Large safety-net hospitals such as Los Angeles County + USC Medical Center were seeing fewer patients.

These resident-run clinics, the bedrock of residency training, were rapidly disappearing. The resident-run clinics were often the only care the indigent patient had. The graduated responsibility for the care of these patients was an important component of the resident's educational experience. The teaching hospitals provided a sense of service to the patient. Patients trusted the system. They believed the residents and attending staff would do right by them and solve their medical problems to the best of their ability.

Although Medicare and Medicaid did diminish the undesirable effect of a 2-class medical system - charity-resident care versus care with a private attending physician-it did impact training. With the increased access to medical care, hospital occupancy and revenue grew exponentially, creating increased work for the resident. The demands of service began to challenge the quality of resident education. 
With federal funds came an increasing amount of paperwork and documentation. Suddenly, the resident was admitting and discharging increasing volumes of patients.

The impact on surgical education was dramatic. Time for investigative inquiry and patient care had been transformed into ordering a battery of tests to cover the particular organ system, hopefully not missing anything, and passing this information up the command chain. Surgical residents had less time to be in clinics or to understand why a particular operation was being recommended. Rather, the patient often appeared on the operating room schedule with a diagnosis and procedure in place. ${ }^{1}$ This approach violated all the principles taught by Halsted. A good surgeon knows when not to operate as well as when to operate. In this emerging paradigm, the resident had little time to contemplate this important part of his or her training.

America was now experiencing unsustainable growth in healthcare costs. From 1965 to 1990, healthcare costs had risen from $4 \%$ gross national product to $11 \%$ and showed no signs of slowing. ${ }^{1}$ In response, the federal government introduced diagnosis-related groups. Hospitals would now be paid a set payment in advance for a particular diagnosis rather than after the fact for billed charges. The impact was a reduced hospital margin and more stresses on resident education. Residents were now seeing even more patients with hospital stays of 2 to 3 days, which before diagnosis-related groups would have been 4 to 6 days. The consequence was more work and ever-increasing service over education. This resulted in longer work hours, less educational value, less interaction with attendings, and an overall feeling of underappreciation. The 80-hour work week can be seen as a result.

Patients became concerned about care being rendered by exhausted residents. They were not so concerned about the residents as they were about getting suboptimal care. To make matters worse, the medical school debt of most graduates was rising dramatically. By 2004, the average graduate owed between $\$ 105,000$ and $\$ 150,000$. The culmination of these factors produced disaffected residents who wanted to complete their training as soon as possible. During this period of time, there was a paradigm shift from professional education to training and practicing algorithm medicine and surgery without the why. This was a clear departure from the Halstedian principles of resident training. Also occurring was the breaking of the sacred trust that medicine had enjoyed: With rising healthcare costs and overworked residents and staff, patients thought they were receiving a diminished level of care. A rising dissatisfaction with healthcare delivery became a public debate.

I now have gone through what was happening in American residency training from 1889 to the present. These factors also directly affect the training of a thoracic surgeon. The challenges of increasing patient volumes, decreasing physician extenders due to cost containment by hospitals, increasing complexity of patients, and the 80-hour work week are threats to our residencies. We as educators, now as never before, need to think creatively about how to train the next generation. Our training paradigm in thoracic surgery has changed little over this period of time, and yet our clinical practices have been affected by these external influences and by an explosion of technologic advances in both cardiac and thoracic surgery.

We need to attract the brightest and best men and women to CT surgery. We will not succeed if the same training program remains the standard. Generations change, and value systems emerge.

Baby Boomers (1946-1963) put work and career ahead of personal gratification and family. Generation X (19631981) and Millennials (1982-2000) do not share the preoccupation with work that Boomers did. Life balance is very important to this new generation. They want to have families and attend their children's soccer games. In training the next generation, we have to keep this in mind. Interestingly, this is just important to men as to women.

If we are the Halsteds of the 21st Century and are tasked with designing the new training paradigm for thoracic surgery, what are the factors to be considered? First, we should consider the length and composition of our training. Second, how do we train the next generation of academic leaders and mentors? Third, how do we recruit the next generation with an emphasis on diversity and inclusion? Fourth, how do we restore professionalism as a basic tenet? This is not meant to be all inclusive, but highlights some of my personal thoughts.

\section{LENGTH AND COMPOSITION OF TRAINING}

The average length of training after medical school for a CT surgeon is 8 years. In a workforce survey by Shemin and Ikonomidis, ${ }^{3} 25 \%$ of adult cardiac surgeons, $56 \%$ of congenital surgeons, and $32 \%$ of general thoracic surgeons reported training exceeding 9 years. And if we break down the years of training, most spent 5 years in general surgery before thoracic surgery. Although I believe the number of years can be shortened, a substantial decrease is unlikely if we want to train the best thoracic surgeons. However, the time spent has to be carefully reevaluated. Given the changes that have occurred in General Surgery, 5 years spent learning techniques of stapling the bowel, liver resections, and Whipple procedures is not time well spent. However, we do need to work with General Surgery in the first 3 years to design rotations that work for CT surgery trainees and do not disrupt the overall general surgery rotations. The constant paradigm shifts of clinical care demand more flexibility in our training programs, and therefore more focus on deliberate training in thoracic surgery. We need to offer training programs that can be modified easily as our clinical practices change and as technological advances continue. As has often been said, "the only constant is change." 
I would propose a 6-year training program with an optional 1 or 2 years of research for those residents pursuing an academic career. The first 3 -year block of training would be dedicated to basic surgery and cardiovascular training. During the first year, residents would spend 7 months in general surgery services and learning about critical care, acute surgical emergencies, and trauma. The next 5 months would be spent on cardiovascular rotations in which we would teach the basic skills of opening the chest, cannulation, and vascular suturing. Cardiology rotations, including catheterization laboratory and echocardiogram reading, would be offered.

During the second year, 7 months of general surgery would be again offered in basic patient care areas as well as some of the surgical subspecialties, and then 5 months on cardiac and cardiology rotations. During this year, rotations in congenital heart, perfusion, and wire skills would be offered.

In the third year, 3 months on general surgery performing acute-care surgery and 9 months on the thoracic and cardiovascular services would be offered. The first 3 years will produce a resident who is competent with acute surgical care and armed with basic cardiovascular and thoracic skills.

After 3 years, residents may elect to spend 1 or 2 years in research. At USC, a structured program is in place to give courses in statistics, grant writing, and research conduct as outlined by the National Institutes of Health. We believe this program prepares the resident for a career in academic surgery. On average, each resident completing this program has produced 3 clinical papers with at least 2 podium presentations. This is a year spent with a mentor. The resident is exposed to a role model in academics with the hope of stimulating an increased interest in investigative research.
The last 3 years are clinical years with graduated responsibility. The resident sees all aspects of cardiac surgery, transplantation, cardiac support devices, and thoracic surgery. Residents operate early in their fourth year and in years 5 and 6 are usually the operating surgeon (Figure 3). We believe this produces a thoracic surgeon who is a good doctor, surgeon, and scientist.

I often challenge our faculty about resident competency. The litmus test for me involves 3 questions: Would you hire the graduate as a faculty member? Would you let the graduate operate on a family member? Would you let the graduate operate on you?

If the answer to these questions is yes, then the ultimate bar of competency has been reached. Much like Dr Sawyers challenging me to be his surgeon, this ultimate bar has remained my goal in resident teaching (Figure 4).

As outlined, the length of training could be abbreviated, and the composition would be more focused on CT surgery. If we want to attract the very best, our training has to be focused more quickly on the specialty these Millennials have chosen. With increasing debt out of medical school, these residents want to focus early and finish as quickly as is reasonable.

This model of training in which the predominance of the postgraduate training is spent in your chosen specialty seems optimal. As our specialty becomes more highly subspecialized, this extra time can be used for specialized training tracks within our overall training program. As is currently being discussed by the American Board of Thoracic Surgery, training tracks for thoracic, adult CT, and adult structural surgery could be easily accommodated.

It is important that we take responsibility for training our residents and not leave it to another specialty. Adult

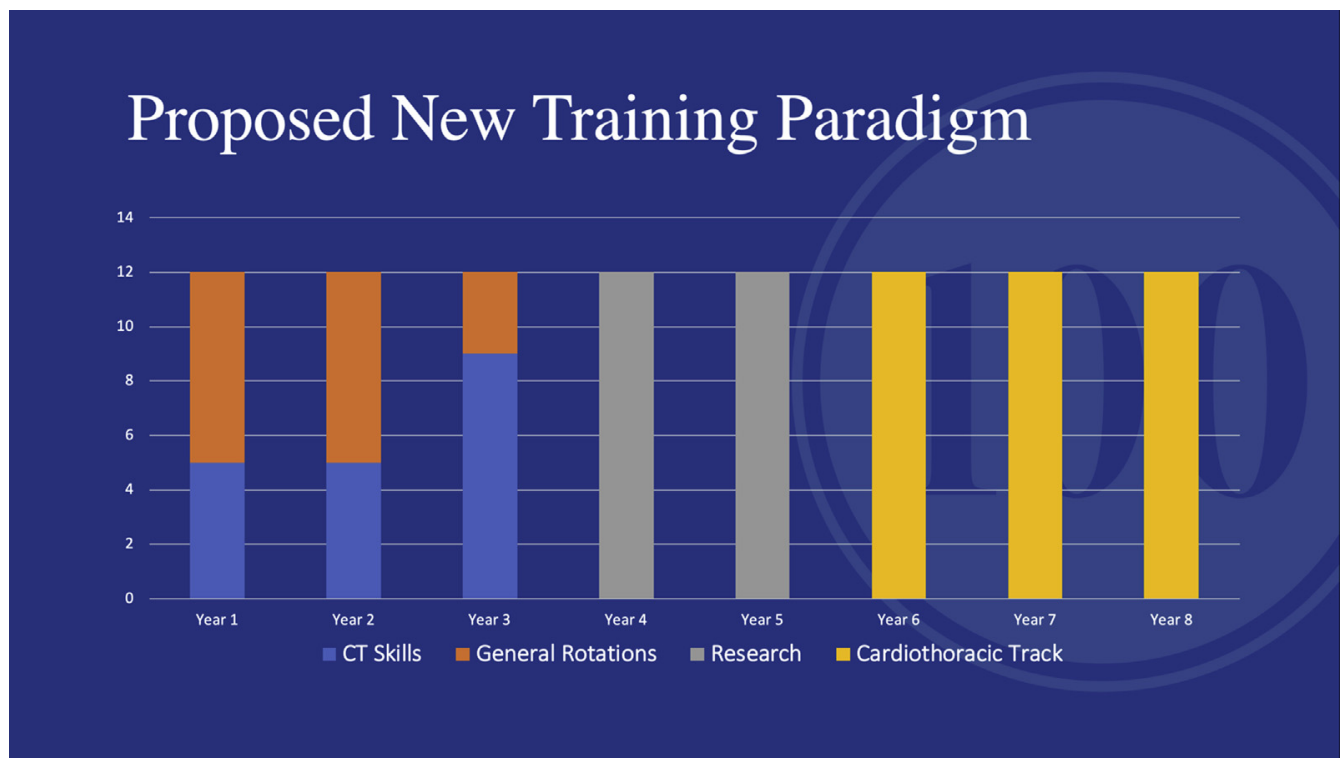

FIGURE 3. Proposed new training paradigm. 


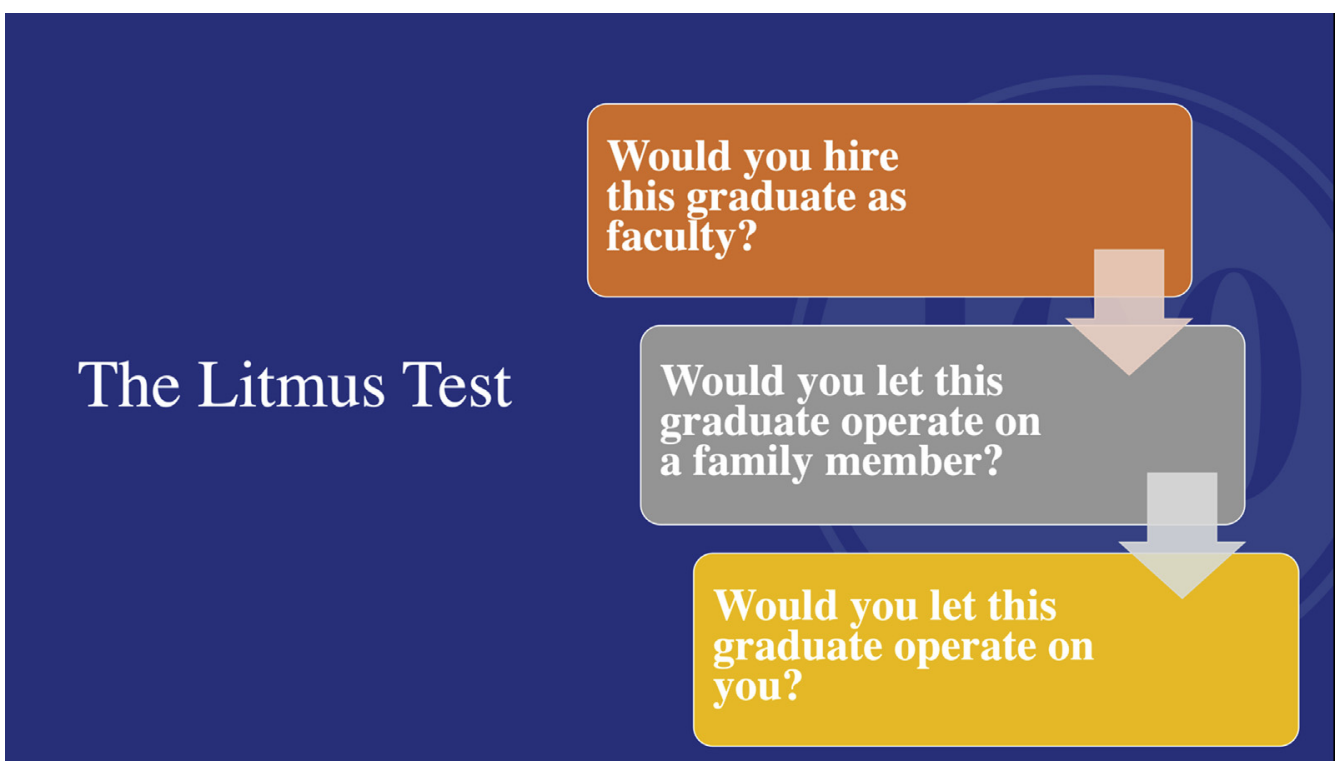

FIGURE 4. The litmus test for resident competency.

cardiac surgery is becoming more catheter based, which is integral to the future practice of cardiac surgery. There is a debate about who should train the resident in these skills. The practice of thoracic surgery over the past 100 years has changed dramatically. We have gone from tuberculosis surgeons to surgeons performing highly complex cardiac and congenital heart procedures with cardiopulmonary bypass. With each incremental and sometimes revolutionary technologic advance, we have been able as a discipline to teach the next generation those needed skills. Hopefully, we also taught that surgery and medicine in general are dynamic and will continually change and practices will continually evolve.

Catheter-based intervention is another such point of technologic advancement. There is much debate about who should train the resident in these skills. As thoracic surgeons, we are uniquely positioned to train this technology because we understand the underlying pathology. We know what a highly calcified bicuspid aortic valve looks like and why a transcatheter approach may not be the best option for the patient. If I have never seen this valve, my decision-making between a surgical approach versus a catheter valve may be influenced by my personal goals and ability. Catheter-based technology will affect not only valvar diseases but also aortic pathology.

Endoaortic stenting has revolutionized complex aortic pathologies of dissection and aneurysm. Operating on patients with ascending and descending aortic disease can now be accomplished routinely by combining open ascending and arch debranching with a distal frozen elephant trunk, setting the stage for future distal aortic stenting. In the recent past, this operation carried out with an open technique would have had high morbidity and mortality. Now, using an endovascular procedure combined with an open procedure, the expected morbidity and mortality are much lower.

These complex operations are being taught to our residents using the wire skills they will need in the future. The wire skills needed to negotiate the arch and head vessels are applicable to the aortic valve. The merits of a fellowship in "structural heart disease" after CT training have to be carefully analyzed. Is the objective to gain a skill we believe we cannot teach or access to patients we think will not be available?

A year is a long time to let the camel keep his nose under the tent. Remember, our goal is to shorten as best we can the resident training program.

\section{THE NEXT GENERATION OF ACADEMIC LEADERS}

This may be our greatest challenge, and it is certainly the most important. In the current era of managed care, increased demand for shorter hospital stays, cost-cutting by decreasing the number of physician extenders, and greater administrative overhead, the resident has assumed an increased service role at the expense of their education. Time for cognitive pursuits is continually under assault by clinical demand. For example, the topic on surgical rounds is often not about the latest article on prosthetic valve endocarditis but on the disposition of the patient and going home with family or to a skilled nursing facility. The triage of patients is an increasing role of our residents and has little educational value. If this environment is to change, we have to be part of the solution. We have to advocate for 
more physician extenders, more administrative help on the floors for patient triage, and in some circumstances an increase in the resident pool.

Mentoring and role modeling are key to fostering interest in academic surgery. We have to stimulate excitement about presenting at the next annual meeting of the AATS. We have to take an interest in their research and help them achieve success. Once they have experienced the thrill of that first podium presentation or that first paper accepted with their faculty mentor, most will be hooked. I can remember my first presentation on lobar lung transplantation at the 75th AATS Annual Meeting. I was very excited to be presenting, but even more so because sitting in the audience was my mentor, Dr Shumway. Those moments you never forget. Time for reflection and discovery have to be part of our training programs. A year or 2 spent doing productive research is the platform from which the next generation of academic leaders will be launched. Stay engaged with the residents, show interest in their work, and celebrate their accomplishments. This is the culture that will produce the next generation of leaders.

\section{RECRUITMENT OF WOMEN AND MINORITIES TO OUR SPECIALTY}

The number of women entering medicine has been steadily increasing. In 2017, women surpassed men enrolled in US medical schools, making up $50.7 \%$ of students compared with $9.3 \%$ in 1965 to $1966 .{ }^{4}$ This is a pool of medical students we have to attract to our specialty. We note in the last Society of Thoracic Surgeons/AATS survey that $48 \%$ of practicing surgeons have made the decision to pursue thoracic surgery while in medical school. ${ }^{5}$ We at USC have certainly seen great enthusiasm for the I-6 program among highly qualified medical students. We have to reach into the medical school classes and convince this growing female workforce that a career in CT surgery is a great career. Lyons and colleagues ${ }^{4}$ reported with the increasing numbers of female medical students, women going into surgery has also increased from $15 \%$ in 2000 to 2005 to $24 \%$ in 2016 to 2017 . During the same timeframe, women going into CT surgery has increased by only $3.2 \%{ }^{5}$

The statistics for underrepresented minorities (URMs) going into medicine in general are dismal. African Americans and Hispanics represent $14 \%$ and $17 \%$ of the US population, respectively. However, they represent only $4 \%$ of the physician workforce. ${ }^{5}$ If we look at current trends in US medical schools, although improving, the number of African American students represent $4.6 \%$ and Hispanics represent $5.7 \%$ of graduating medical students. ${ }^{5}$ The challenge here is far greater because of the small numbers. If we are to recruit women and URMs to our specialty, we have to understand more fully the barriers.

Borrowing from the Society of Thoracic Surgeons Workforce on Diversity and Inclusion, Cooke and colleagues ${ }^{5}$ identified 4 frequently cited barriers for women and URMs from entering CT surgery: first, lifestyle concerns for a career in CT surgery as it related to family planning; second, a lack of women and URMs as mentors and role models; third, a lack of exposure to CT surgery for women and URMs at the medical student and surgery resident level; fourth, a perception of an unconscious bias by CT programs toward women and URMs (Figure 5).

Lifestyle concerns do not just affect women and URMs, but the majority of medical students entering the workforce.

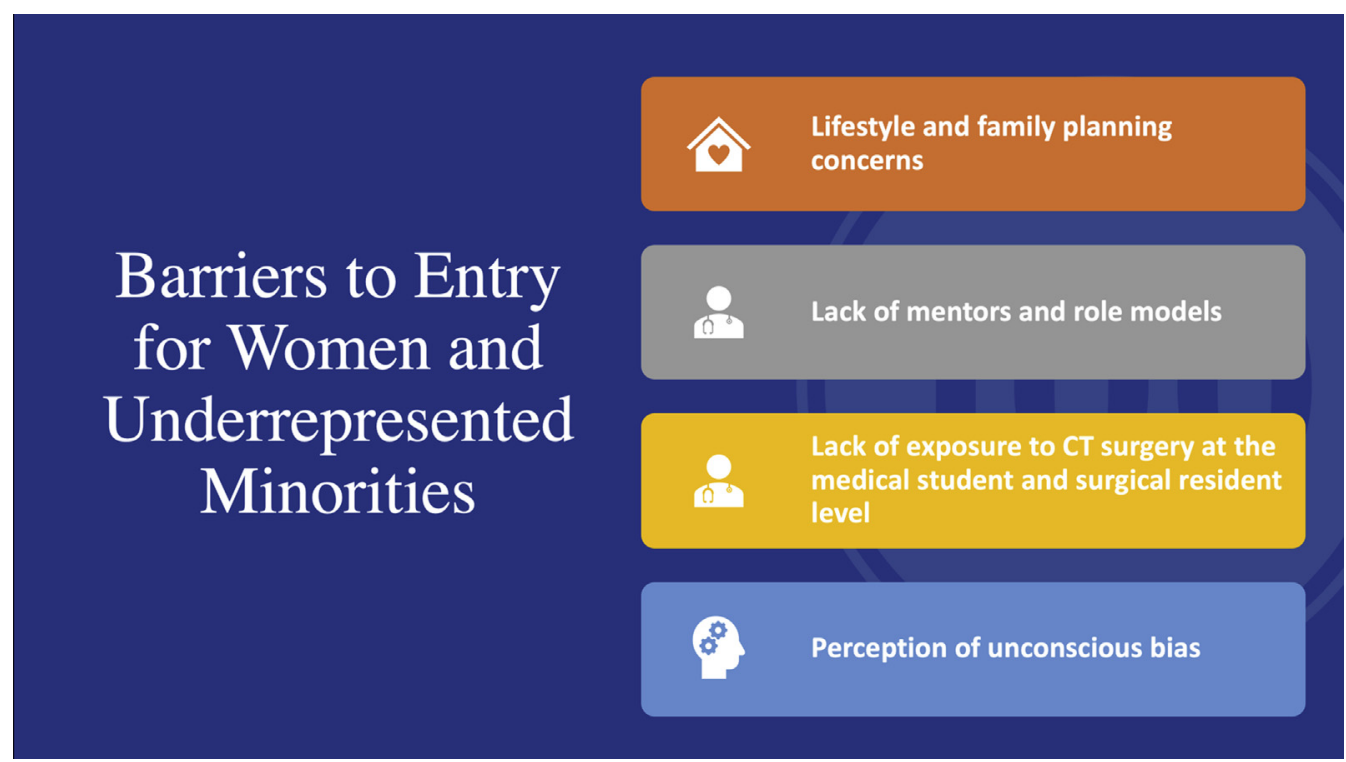

FIGURE 5. Barriers to entry to CT surgery for women and URMs. 
The 80-hour work week has been helpful for students thinking about surgery. We must explore more flexible training paradigms for women with families or planning to have a family. A simple but important first step would be to provide childcare in our hospital or a nearby facility for female and male residents. This is often a major hurdle when money for hiring care is limited.

The lack of mentors and role models needs to be actively addressed. With more women and URMs currently entering the surgical workforce, over time there should be more women and URMs in leadership positions. This "pipeline effect" has often been the explanation for so few women in leadership. Looking closer, Cooke and colleagues ${ }^{5}$ found that female CT surgeons accounted for $61 \%$ of assistant professors and $18 \%$ of full professors, representing a larger fall-off than expected. CT leadership has to constantly be vigilant to provide support and encouragement to our young women and URM faculty members. We need to place them on local medical school committees, promote national organization involvement, encourage their involvement in annual program planning, and propose them as moderators of sessions. We as role models have to make them more "visible" to the academic leadership and help them realize this great resource and potential for our specialty.

The importance of diversity-and that includes race, sex, and sexual orientation - has been documented in many disciplines. Businesses with women and URMs on their staffs and boardrooms consistently show better financial performance. ${ }^{6}$ In surgery, women leaders have brought positive changes, such as promoting diversity and inclusion, championing pay equity, and addressing issues such as wellbeing and burnout. As the population in the United States has become more diverse and with more women in medicine, it is an imperative for our specialty to be more inclusive. Last year, the AATS Leadership Academy assembled a group of future women and URM leaders to discuss issues related to career satisfaction, academic promotion, and life balance, and how to attract more women and URMs to our specialty. I believe the AATS will play an important leadership role in making CT surgery more inclusive. Just as we were founded on being inclusive of all disciplines related to thoracic surgery, I am sure Willy Meyer would encourage us to be inclusive in our membership. I do have a pertinent disclosure, as I am the proud father of an Academic female surgeon.

\section{PROFESSIONALISM}

I think we all have heard of the erosion of the social contract between medicine and society. The establishment of that contract was at its peak during the first half of the 20th century. That era was noted for the discovery of new medicines, such as insulin, that produced life-changing results. In cardiac surgery, the blue baby operation, the first attempts at intracardiac repair, valve replacement therapy, and coronary surgery were all important technological advances that changed people's lives. As a result, there was good will from the American public for medicine and doctors. A social contract had been entered: There would be public funding for the ever-growing healthcare costs as long as the product, good health care, was provided.

Over the next 35 years (1965-2000), there was an erosion of that trust. Best-selling books began to appear with titles such as How to Survive Your Doctor's Care, ${ }^{7}$ Surviving Health Care, ${ }^{8}$ and, my favorite, How to Get the Same High-Quality Health Care Your Doctor Gets. ${ }^{9}$ Why did this happen? During this period of time, there was doubledigit healthcare inflation. Various models of health maintenance organizations entered as a way to control costs. What got lost during this time was the patient and the doctorpatient relationship.

As a profession, we were on a treadmill to see more and more patients and do more procedures to make up for the declining clinical revenues. Academic faculty were being replaced by clinical productive faculty, and the teaching mission was being threatened. Patient encounters with their physician would often be brief, and the patient would leave with the feeling she was not heard. As thoracic surgeons, we were guilty of expecting a patient flow from the cardiologist already with a diagnosis (aortic stenosis, coronary disease), and we provided the necessary procedure. That pipeline seemed secure as long as the cardiologists were not involved in the treatment, that is, a procedure. We now find ourselves potentially competing with cardiologists for the patient. This is not the environment we want to be in, nor is it the environment the cardiologist wants. We must remind ourselves that patients do not exist for the benefit of the doctor: The doctor exists for the benefit of the patient.

As catheter-based technologies have brought cardiology and cardiac surgery together with options for valve replacement therapy (transcatheter aortic valve replacement or surgical aortic valve replacement), we must always advocate for the patient without our self-interest as a determinant. As this type of therapy is becoming mainstream, transparency and honest reporting of the data will be demanded, such that appropriate therapies can be recommended. We as thoracic surgeons will have to provide leadership and be the watchdogs as the cardiovascular therapeutic space moves forward. The AATS will be an integral leader moving forward. I am reminded of a quote: "Leadership is not the private reserve of a few charismatic men and women. It is a process that ordinary people use when they are bringing forth the best from themselves and others." 10 This will ensure that future patients will receive the best therapy. If we remain strong advocates for our patients, our specialty will have reestablished the social contract, which will ensure our future.

I have outlined what I believe the CT training programs of the future should look like. I have also delineated some 
of the challenges we will have to address: length of training, increasing recruitment from the increasing pool of women and URMs, professionalism, and training the next generation of academic leaders.

\section{CONCLUSIONS}

To conclude, I would ask each of you one last question: Why does the AATS exist as an organization? My answer as your president is: to promote scholarship, education, and research for the benefit of our patients. I believe our membership will be critical to modifying training programs to address "Thoracic Surgical Education in a Changing Paradigm."

\section{References}

1. Ludmerer KM. Let Me Heal: The Opportunity to Preserve Excellence in American Medicine. New York, NY: Oxford University Press; 2015.
2. Sloan H. The American Board of Thoracic Surgery: a Fifty-Year Perspective. Chicago, IL: The American Board of Thoracic Surgery; 1998. 16-7.

3. Shemin RJ, Ikonomidis J. Thoracic surgery workforce: report of STS/AATS thoracic surgery practice and access task force—-snapshot 2010. J Thorac Cardiovasc Surg. 2012;143:40.

4. Lyons NB, Bernardi K, Huang L, Holihan JL, Cherla D, Martin AC, et al. Gender disparity in surgery: an evaluation of surgical societies. Surg Infect (Larchmt). 2019;20:406-10.

5. Cooke DT, Olive J, Godoy L, Preventza O, Mathisen DJ, Prager RL. The importance of a diverse specialty: introducing the STS workforce on diversity and inclusion. Ann Thorac Surg. 2019;108:1000-5.

6. Pories SE, Turner PL, Greenberg CC, Babu MA, Parangi S. Leadership in American surgery: women are rising to the top. Ann Surg. 2019;269:199-205.

7. Gallin PF. How to Survive Your Doctor's Care: Get the Right Diagnosis, the Right Treatment, and the Right Experts for You. 1st ed. Washington, DC: LifeLine Press; 2003.

8. Kushner T. Surviving Health Care: A Manual for Patients and Their Families. 1st ed. Cambridge, UK: Cambridge University Press; 2010.

9. Soden KJ. Special Treatment: How to Get the Same High-Quality Health Care Your Doctor Gets. New York, NY: Berkley Publishing Group; 2004.

10. Kouzes J, Posner B. The Leadership Challenge: How to Make Extraordinary Things Happen in Organizations. 6th ed. San Francisco, CA: Jossey-Bass; 2017:xii. 